\title{
دور الثقافة التنظيمية في الاتجاه نحو التغيير التنظيمي
}

الأستاذ الدكتور : نور الدين تاوريريت، جامعة بسكرة، الجزائر

الأستاذة: نسيمة بومعراف، جامعة بسكرة، الجزائر

إن التنظيمات ليست بمنأى عن التغييرات الاجتماعية، السياسية، و الاقتصادية

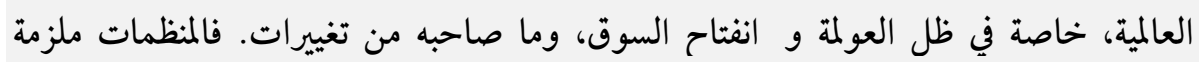

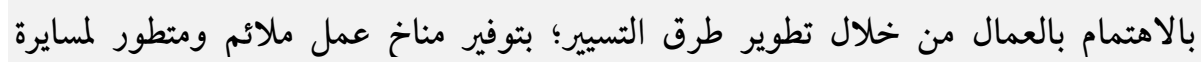

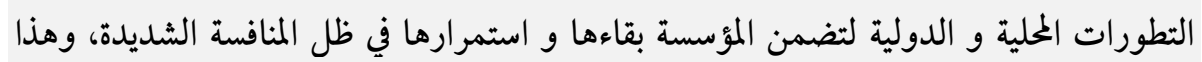

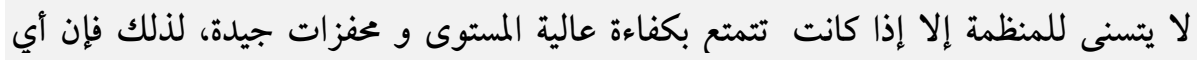

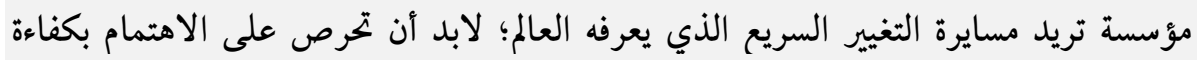

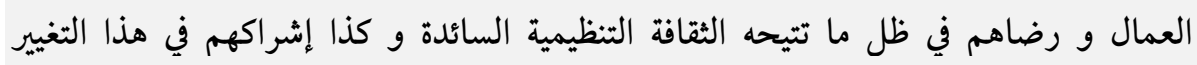
لتحقيق النجاح.

Résumé :

Les organisations ne pas loin des changements sociales, politiques et économiques mondiale; surtout à cause de mondialisation et de coopération du marché, c'est pour quoi les organisations seront obligés de s'intéresser des travailleurs; et ça ne sera pas sans l'amélioration des systèmes et des méthodes de gestion pour suivre les développements intérieurs et extérieurs .

surtout avec la grande concurrence et ça ne se fait qu'à travers une haute performance. avec la coopération des employeurs dans cette amélioration pour mieux faire et pour assurer une bonne résultat. 


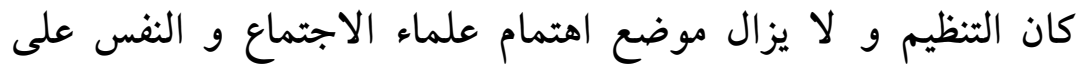

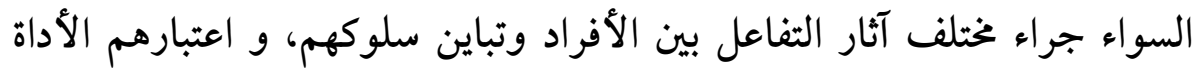

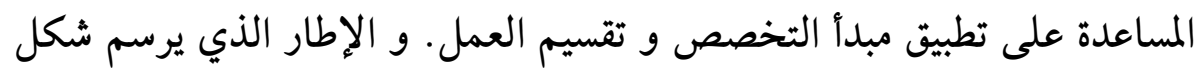

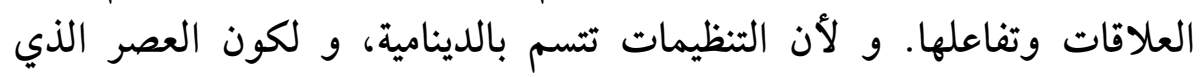

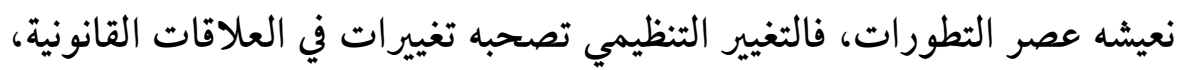

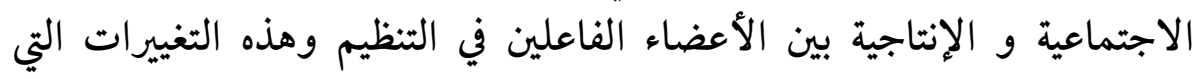

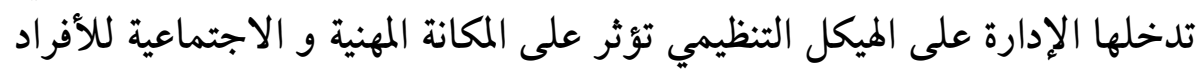

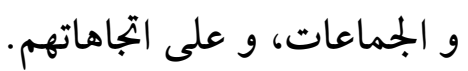

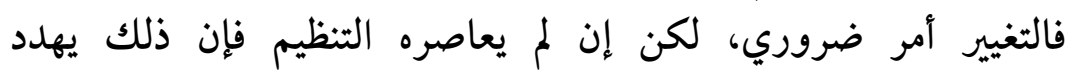

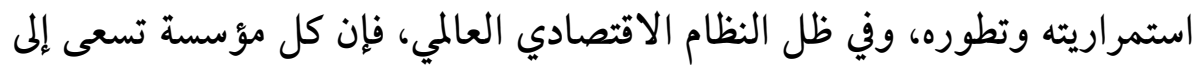

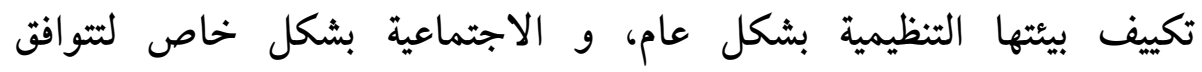

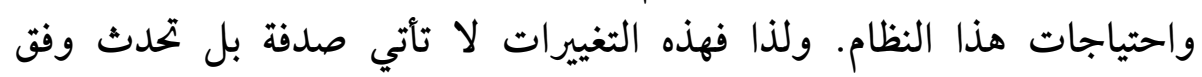

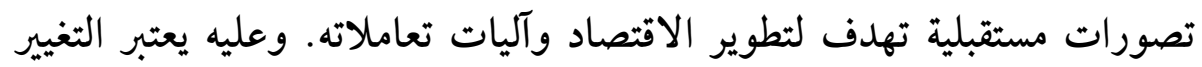

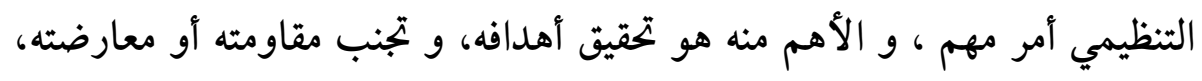

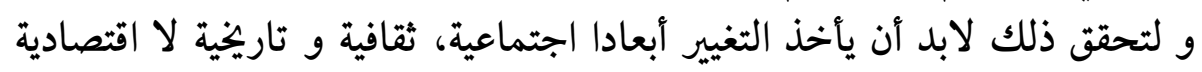

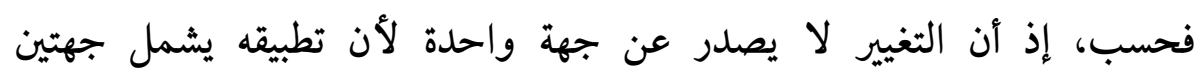

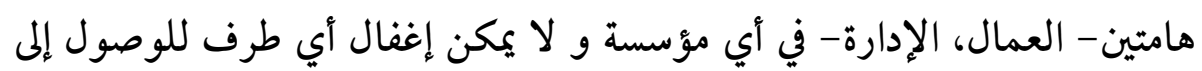

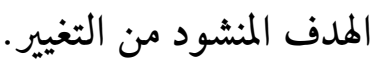
و نظرا لأهمية العلاقة بين الثقافة الثنظيمية و الاتجاه نحو التغيير، فقد الثنام

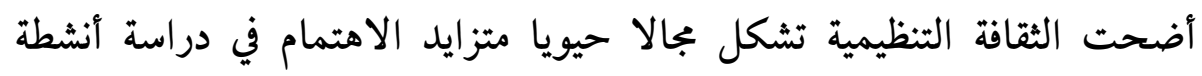

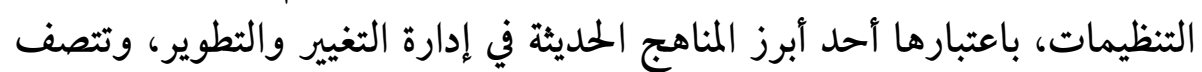

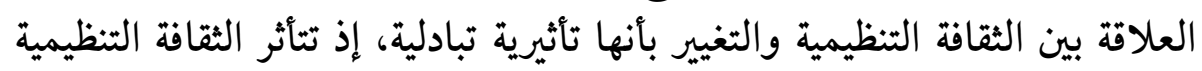

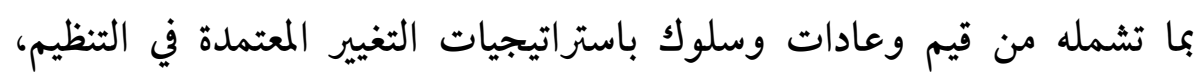

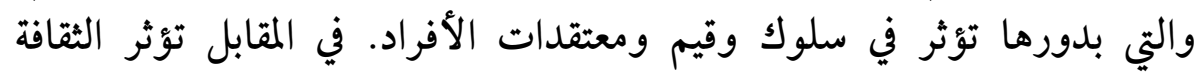


التنظيمية على إستراتيجيات وعمليات التغيير داخل المؤسسة، من خلال دعم

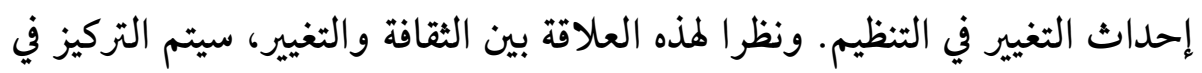

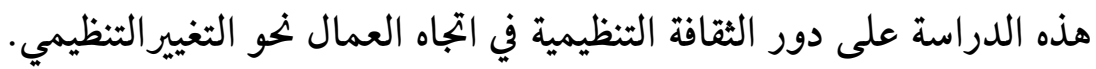

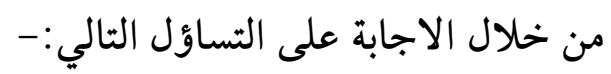

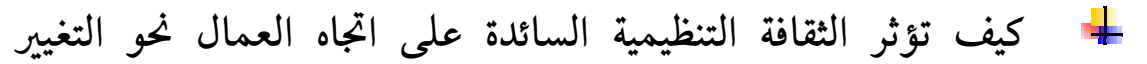

$$
\text { 1. 1. التحديد أهم مصطيم في المؤسسة؟ . التنظيم الدراسة: }
$$

من أهم العمليات التي على القادة الإداريين والمشرفين فهمها وإدراكها،

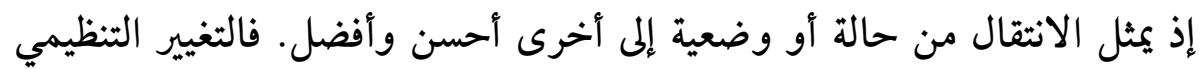

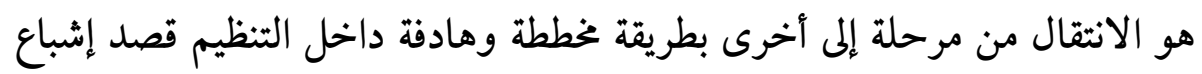

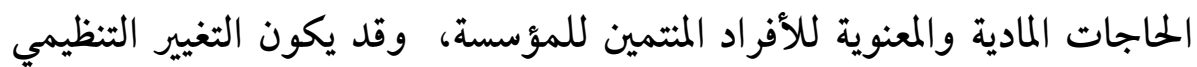

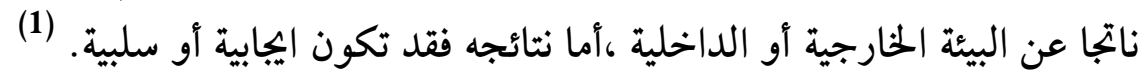

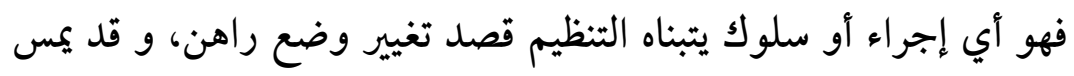

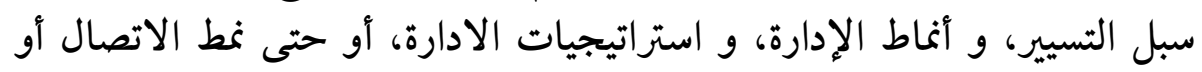

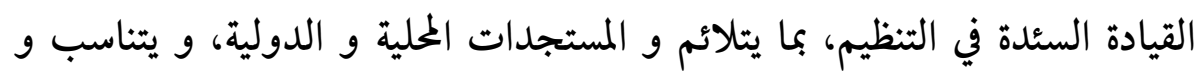

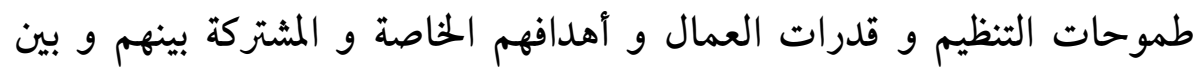
الإدارة.

ب. الثقافة التنظيمية: هي مجموع القيم، المعتقدات، المفاهيم وطرق التفكير

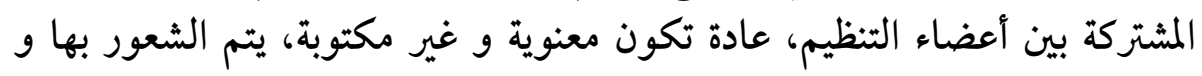
يشارك كل فرد في تكوينها و يتم تعليمها للأفراد الجمدد في المؤسسة.

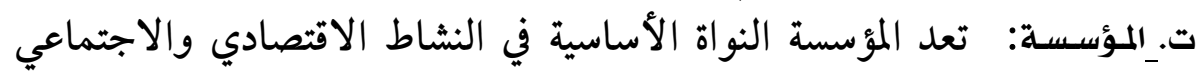

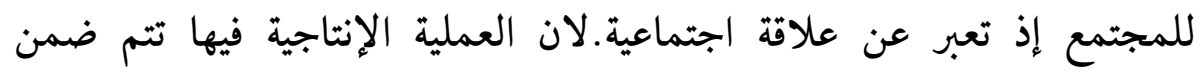

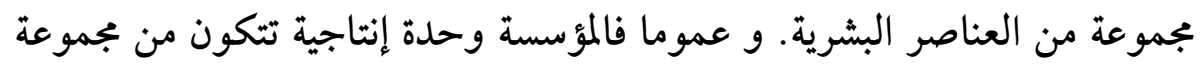
من العناصر المادية (آلات، معدات، أجهزة) والعناصر البشرية (قوة ومدوة عاملة)؛ 
بلجيث يؤدي الاستخدام الجيد والفعال لهذه العناصر مجتمعة إلى تحقيق الأهداف

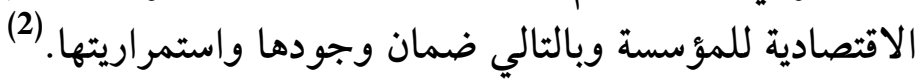

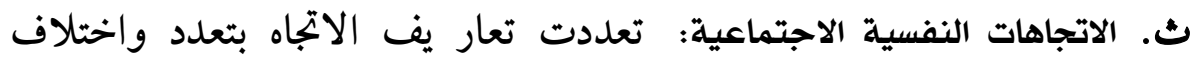
النظريات والمدارس النفسية والاجتماعية للعلماء والباحثين المختصين إلا أننا نجد الندان بندان خطا رابطا ونقطة التقاء بين كل التعاريف المقدمة.

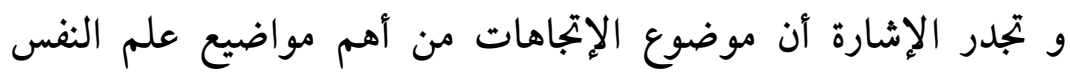

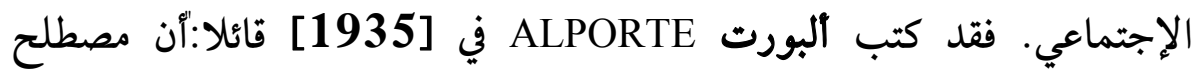

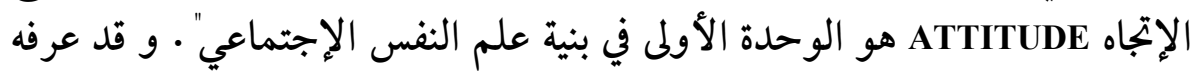

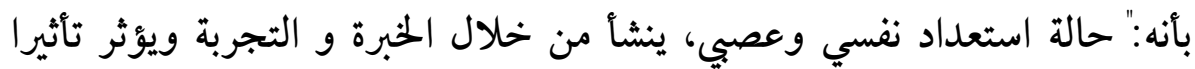

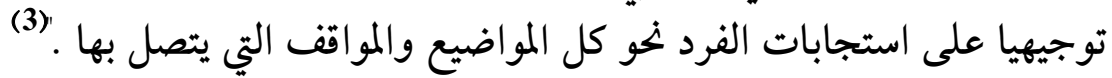
فعملية التوافق عملية نفسو عصبية، يتعلمها الفرد خلال الفيات مراحل حئل حياته

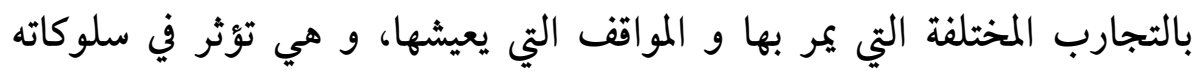

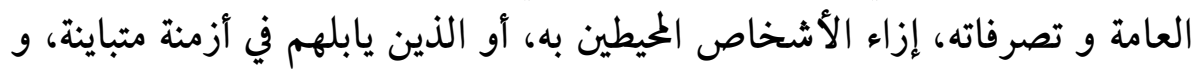

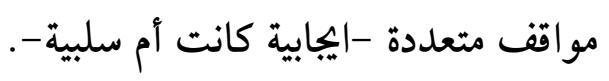

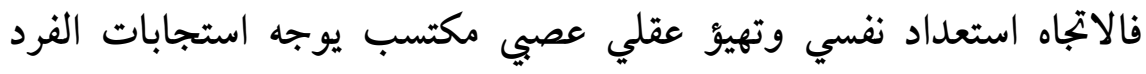

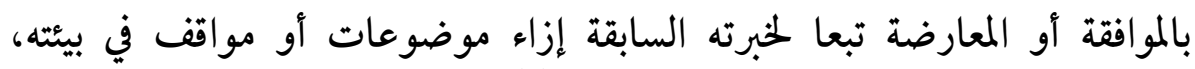
والاتجاه ثابت نسبيا إذ يمكن تغييره وتعديله.

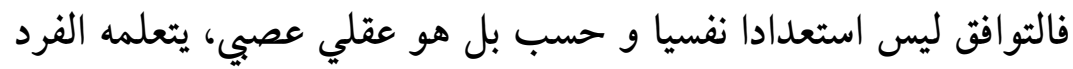

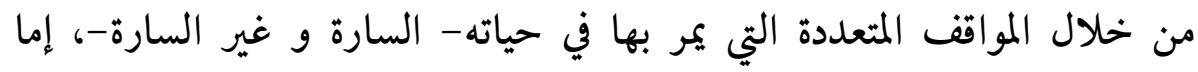

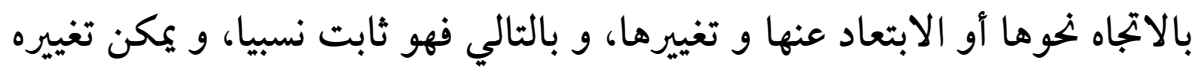

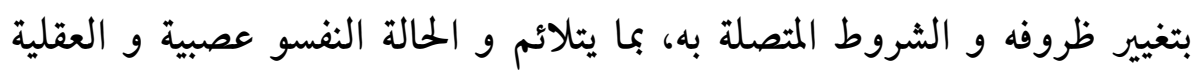
للفرد. 
أولا:التغيير التنظيمي:

1

لأن التغيير حقيقة اجتماعية وإنسانية فإنه لا يمكن إغفالها أو تجاهلها

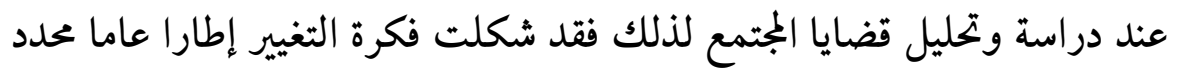

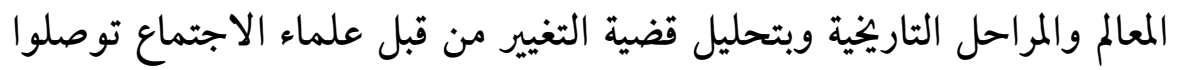
إلى أنه مر بمرحلتين هما:

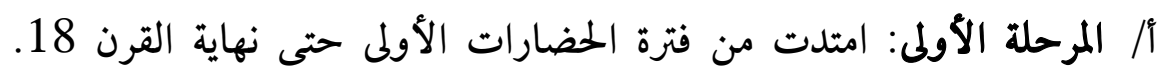

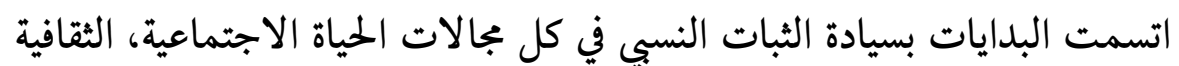
والاقتصادية لسيطرة الإقطاع والتفكير الغيبي عند أغلبية سكان العالم وكات وكان

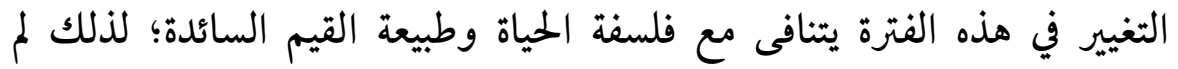

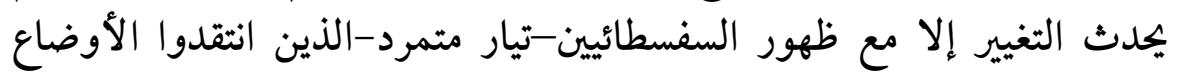

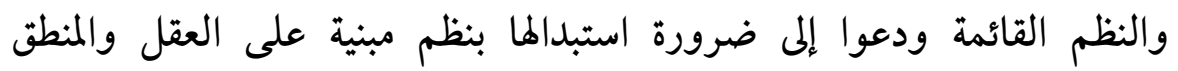
ودافعوا على مبادئ الحرية والمساواة والعدالة الاجتماعية.

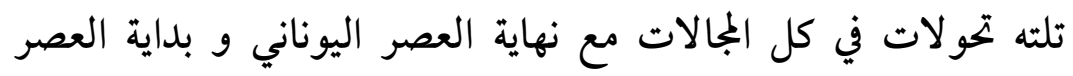

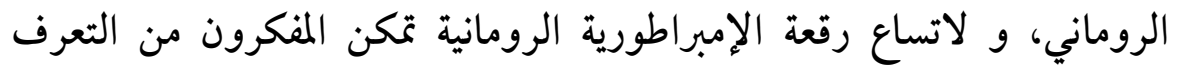

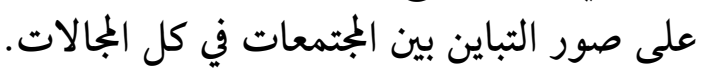

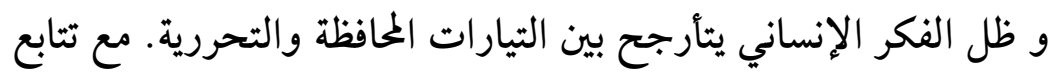
الحركات التاريخية ظهرت التيارات الليبرالية والراديكالية حتى نهاية القرن 19

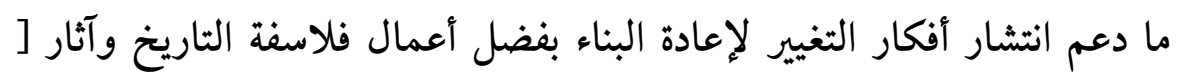

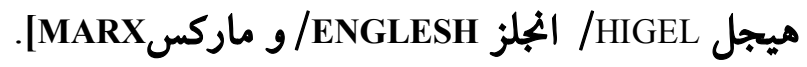
ب/ المرحلة الثانية: امتازت في البداية بنضج الفكر العلمي وظهور الأنساق ماركات

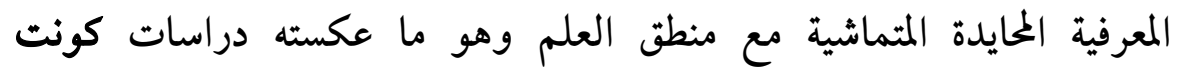
عن الديناميكا و الاستاتيكا وفيبر COMTE ودوركايم E-DORKHEM عن تقسيم العمل. 


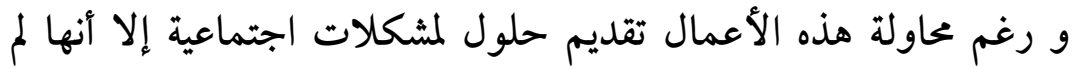

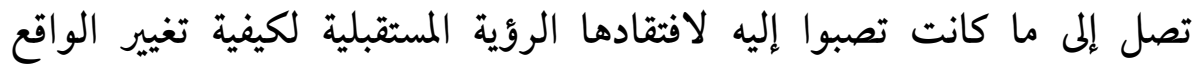

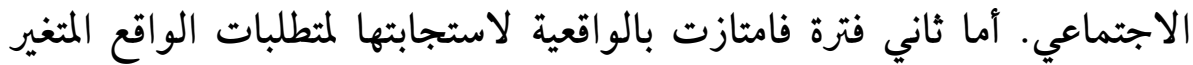

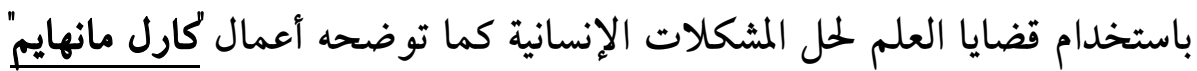
K-MENHAM لأيديولوجياته محددا أبعاده وعو امله والوقوف درس على نتائجه.

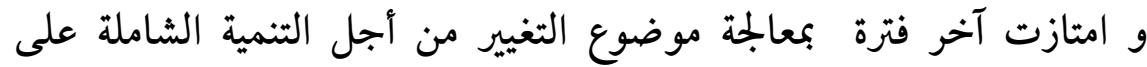

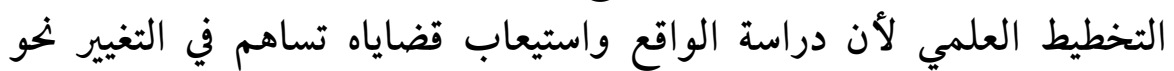

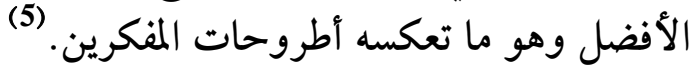

$$
\text { 1 }
$$

التغيير التنظيمي محاولة طويلة المدى للإدخال التغيير والتطوير بطريقة خخططة اعتمادا على أسلوب تشخيص المشكلات بطريقة يشارك فيها أعضاء المؤسسة بصورة جماعية.

يؤكد "الغمري"على عنصر التخطيط في إحداث التغيير التنظيمي بالاعتماد على طريقة حل المشكلات جماعيا ويوافقه أغلب الباحثين على ذلك ذلك لدراسة إسلى التغيرات التي تخضع لها مختلف المؤسسات و بذلك تصبح عملية مقصودة

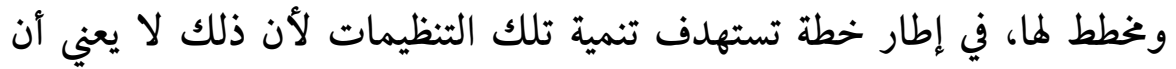

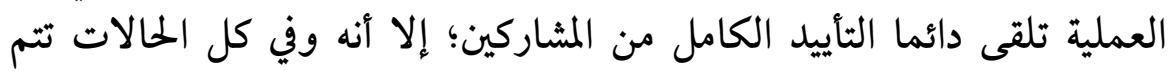

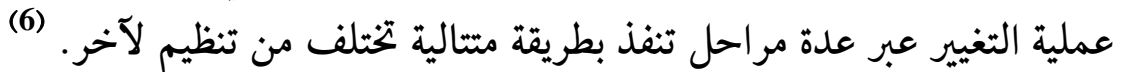

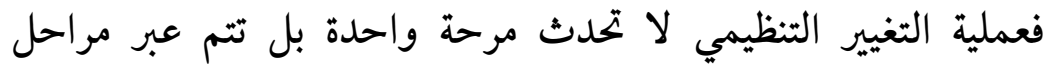

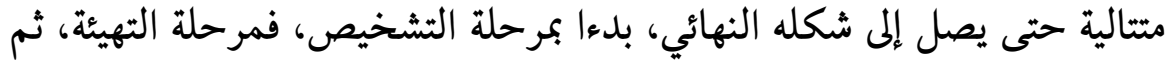

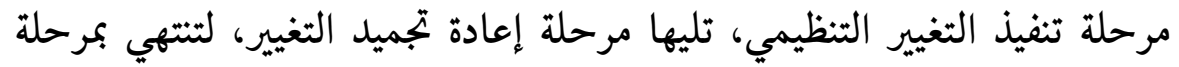

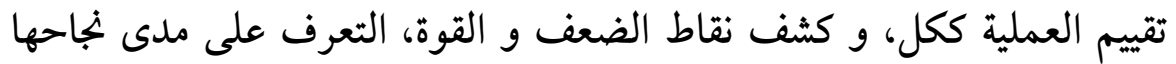

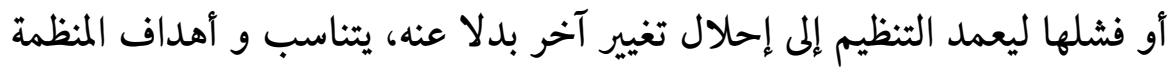
و العمال و تطلعاتهم. 
و فيما يلي شرح موجز لما يتم في كل مرحلة من مراحل التغيير التنظيمي:
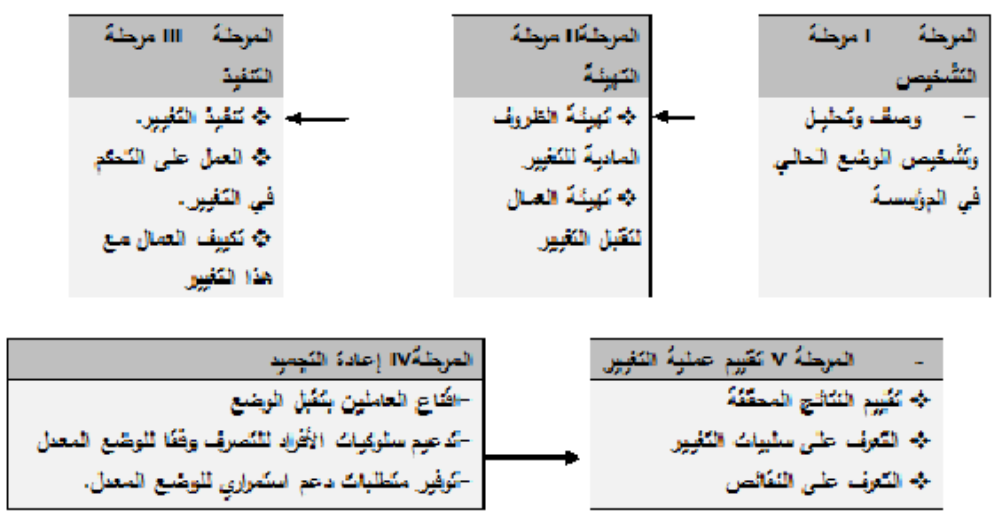

2. 2 أهداف التغيير التنظيمي:

تختلف أهداف التغيير التنظيمي باختلاف تشخيص المشكلات التي تتعرض

لها المؤسسة وعلى كل فهناك جملة أهداف يسعى كل تنظيم لتحقيقها.

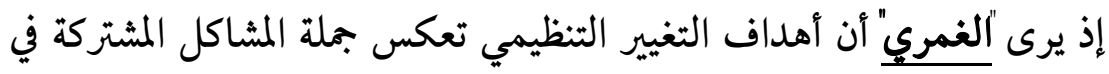

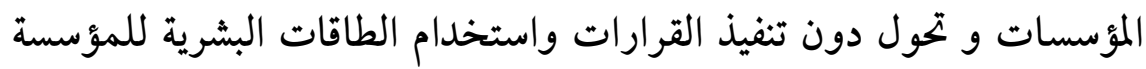

$$
\text { بشكل أمثل ومن هذه الأهداف: }
$$

ل السماح للأفراد التعرف على الاهد ماف: ما يحدث بين أعضاء الجماعة أثناء أداء

$$
\text { مهمتها.( كالاتصال). }
$$

$\checkmark$ لإرساء قواعد الثقة بين الأفراد والجماعات في كل المستويات التنظيمية. 
ل زيادة التعاون بين الجماعات والأفراد المتنافسين. مع وضوح المنافسة

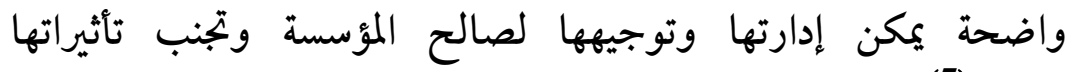
السيئة. (7)

و منه يتضح أن " الغمري" يرى أن أغلب الأهداف المتنظرة من إحداث

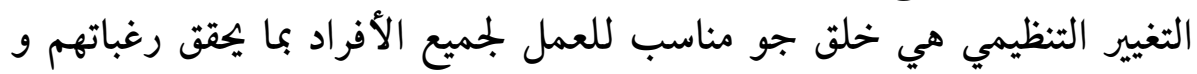

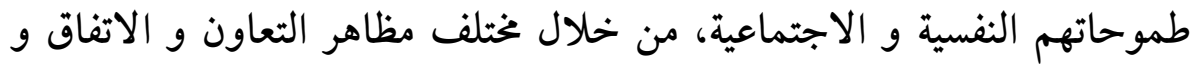
الثقة، و روح المبادرة .... و كلها تمثل عناصر لامبادية للثقافة الثنظية الثنيمية.

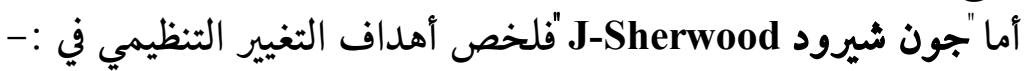

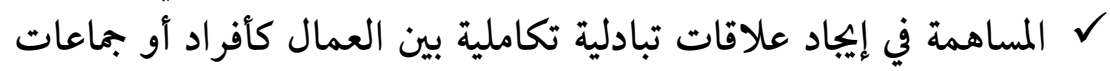

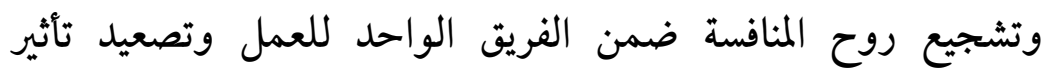

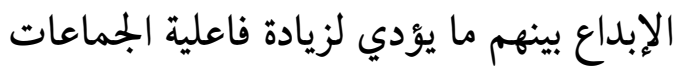

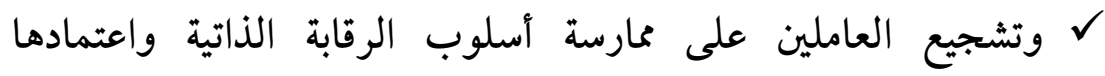
كأساس للرقابة الخارجية. $\checkmark$

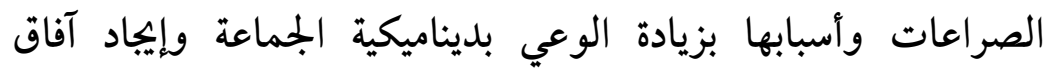

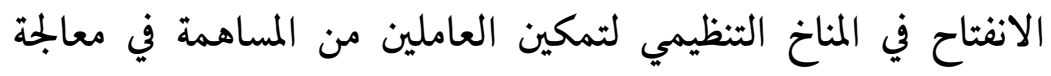

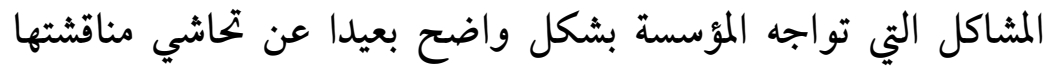
وتحليلها.

$\checkmark$ والديمقراطية في الإشراف كالإدارة بالأهداف بدل الألين أسلوب الإدارية الإدارة بالأزمات. (8)

فالخبراء يتفقون على أهمية إحداث التغيير لضمان استمرارية المؤسسة

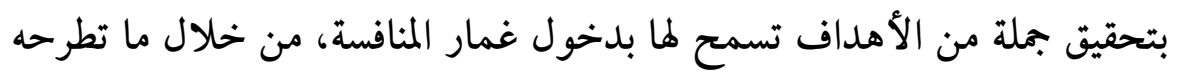

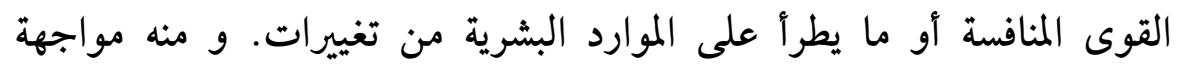

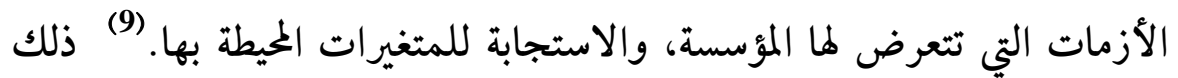


لأن التغيير التنظيمي عملية تعديل للتنظيم قصد زيادة مستويات فعاليته وقدرته

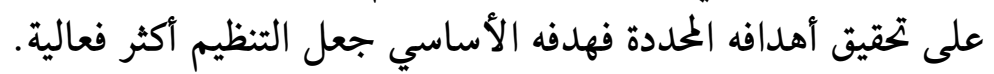
3. القوى الدافعة للتغيير التنظيمي : يسعى التغيير التنظيمي لتحقيق الاستقرار، فهو أمر حتمي لأي تنظيم التيمي

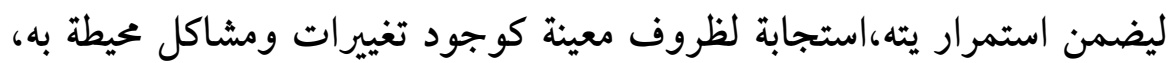

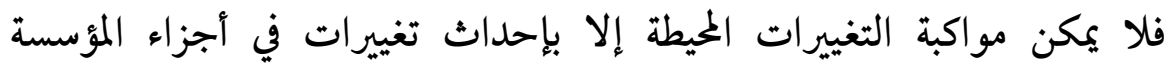
وأسلوب تفكير المديرين في مواجهة مشاكلها. (10)

الشكل رقمر02: مخطط توضيحي للقوى الدافعة التغيير التنظيمي

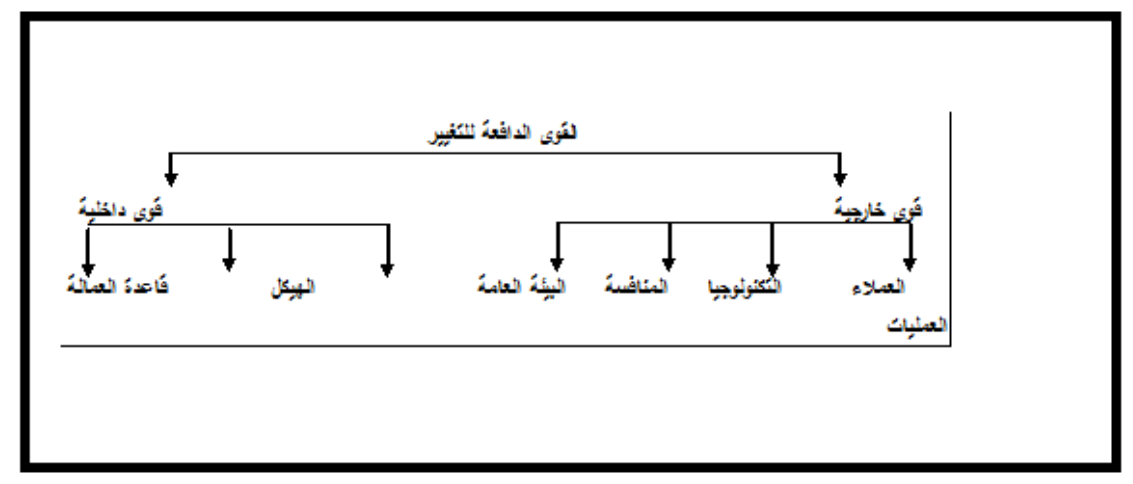

إضافة إلى تغييرات خارجية أخرى، كالتحولات الاقتصادية تجاه

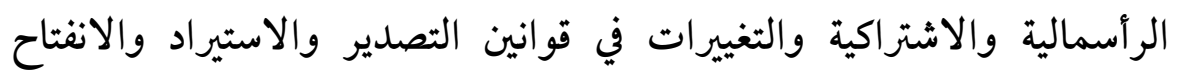

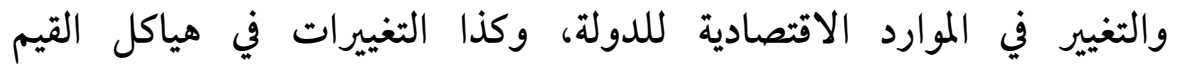
الاجتماعية كقيم التعليم وتطلعات الشباب والتحرر وعمل المرأة.

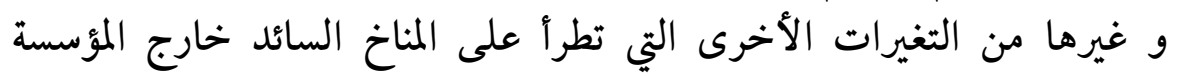
والذي يوجب عليها إجراء بعض التغييرات وفقه لتفادي أي تأثير سلبي له له عليها. 
إلى جانب بعض التغييرات الداخلية التي تؤثر على مصيرها : كالتغيير في

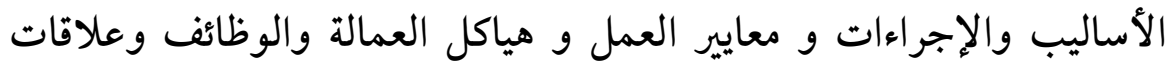

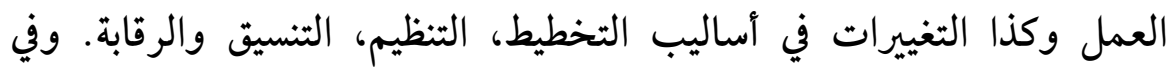

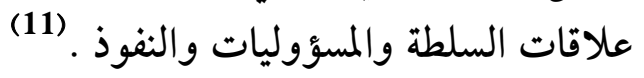

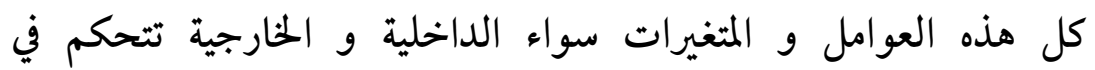
المؤسسة و تحتم عليها ضرورة التكييف والتغيير، لضمان استمراريتها واستقرارها و إلا سيكتب لما الفشل والاندثار.

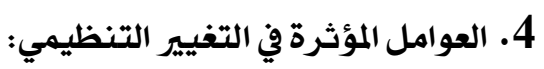

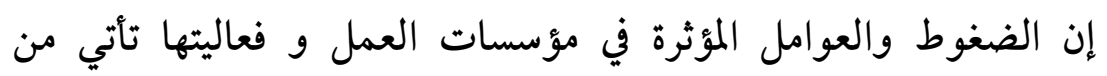

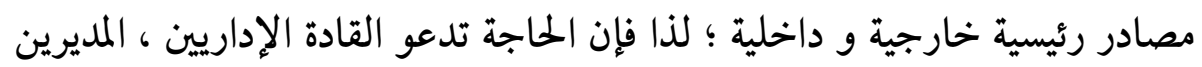

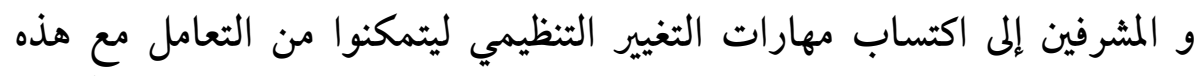

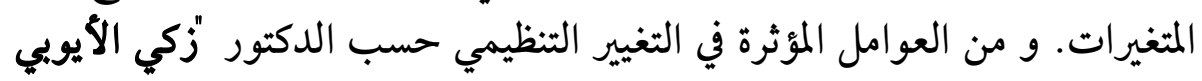

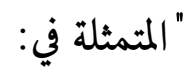

• التوترات و الضغوط الخارجية (البيئة الطبيعية، والتغيرات السكانية ومستوى الثقافة العامة السائدة).

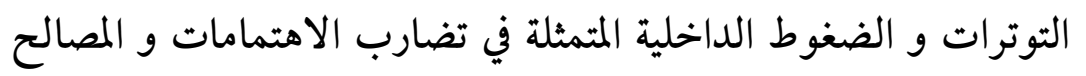

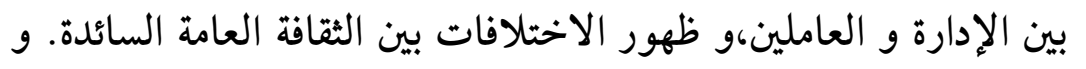

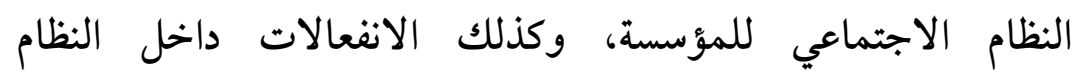
الاجتماعي لنفس المؤسسات عندما تتضارب الأولويات.

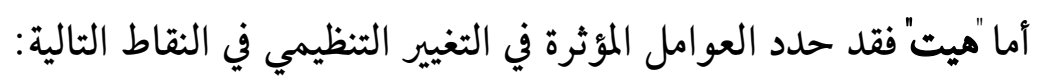

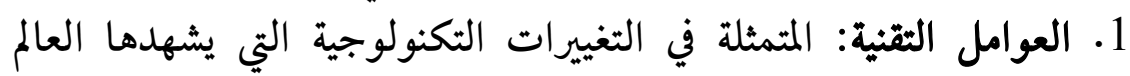

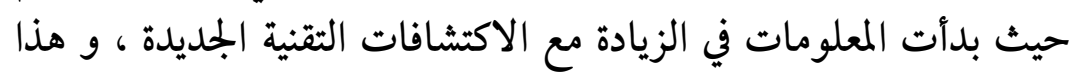

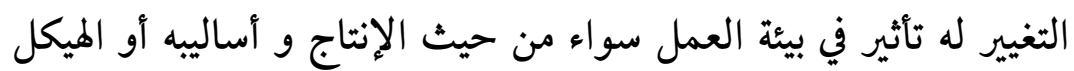

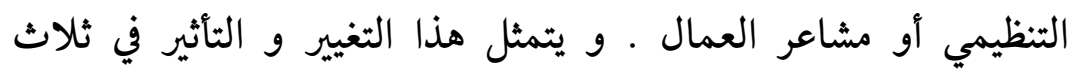

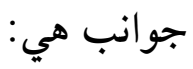




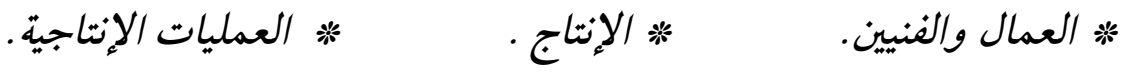

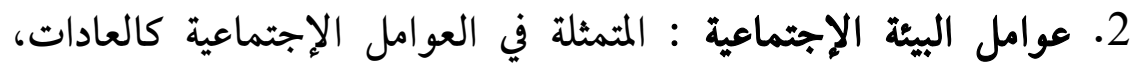

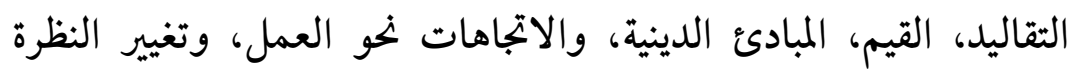

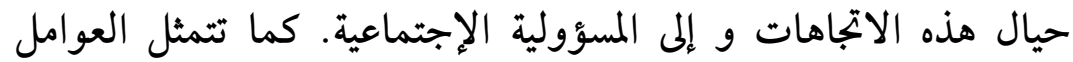

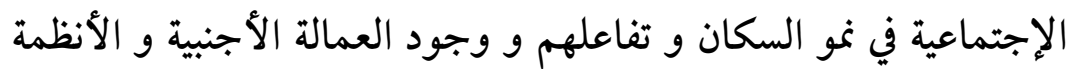

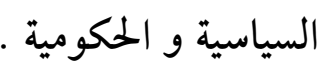

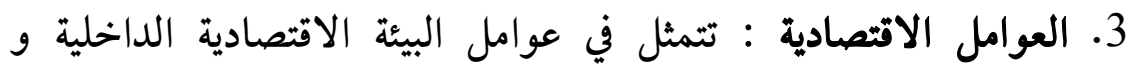

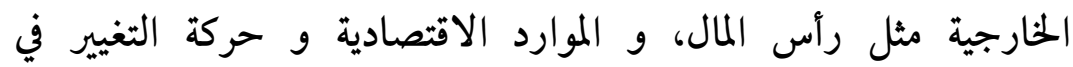

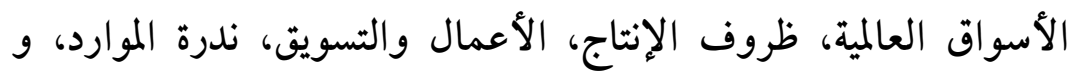
المنافسة أو الأزمات الاقتصادية.

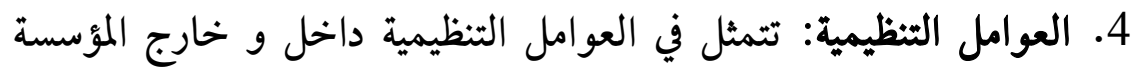

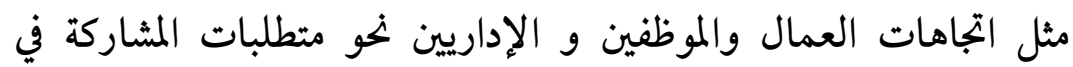

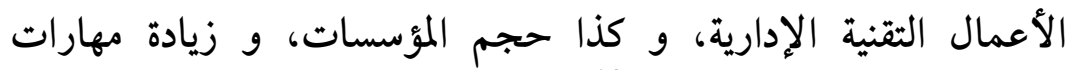

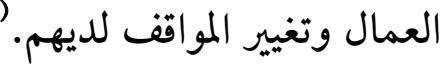
ثانيا: الثقافة التنظيمية:

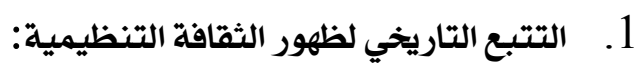

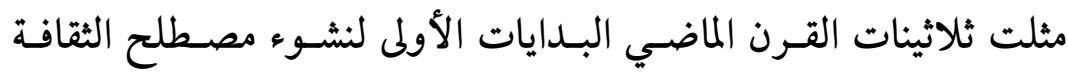

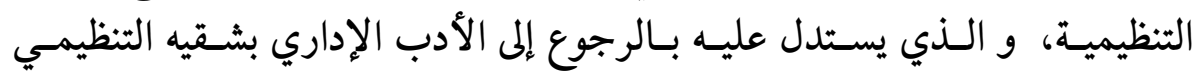

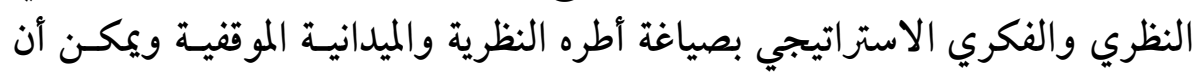

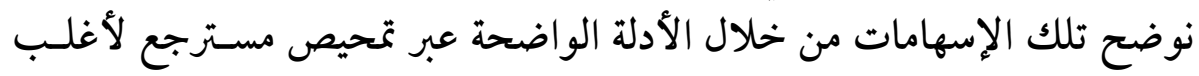
ما كتب عن هذا الموضوع في الأدبيات الإدارية الأجنبية والعربية.

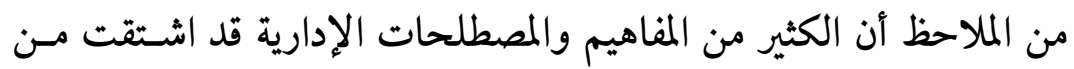

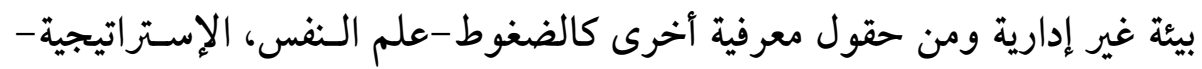

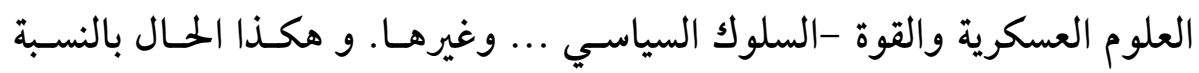
للثقافة التنظيمية فقد تطورت بتطور الإدارة والمنظمات وأخذات الكثير من أبعادهـا

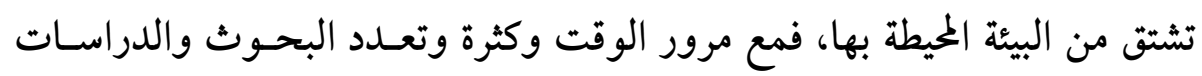




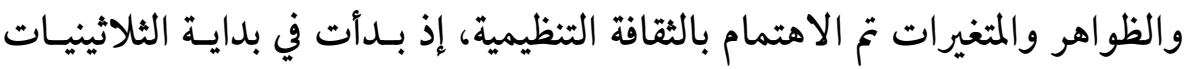
عندما تمت الإشارة إليها بوجود العلاقات الإنسانية في جامعـة شـيكاغو (1934) ثم تجارب مصنع ماوثورن.

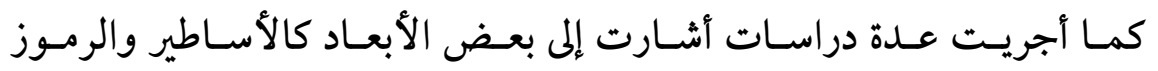

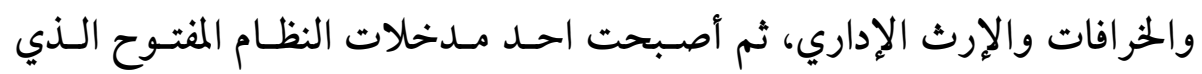

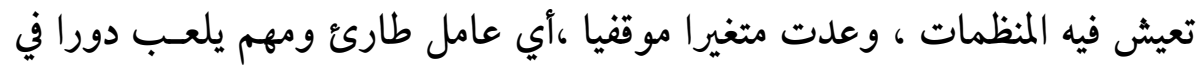

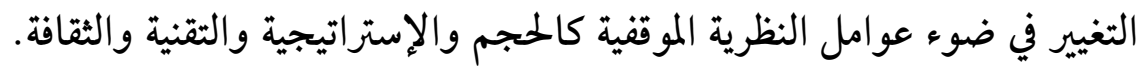

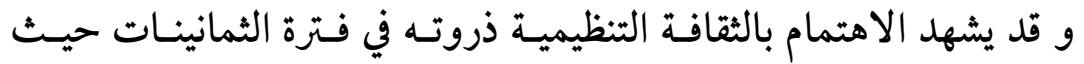

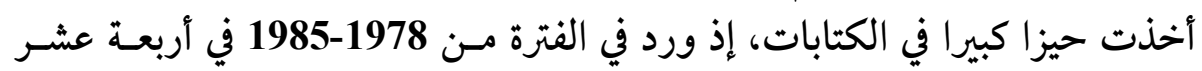

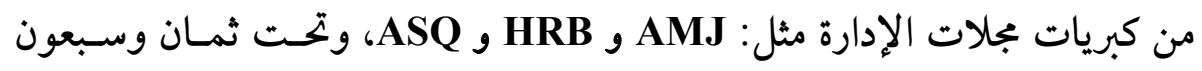

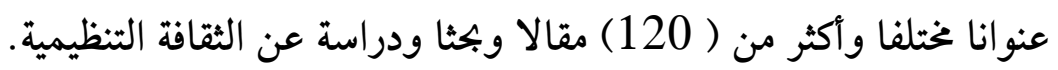

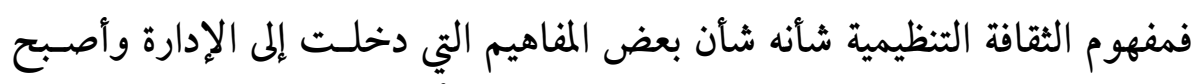

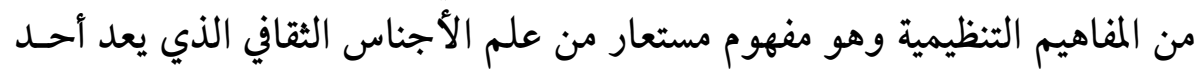

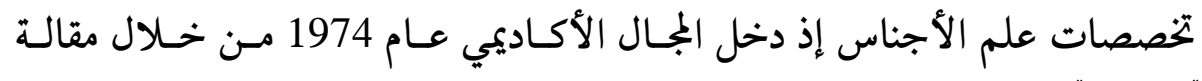

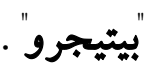
و يمكن تحديد ثـلاث اتجاهـات بشـان فهـم الثقافـة التنظيميـة مـن خـلال

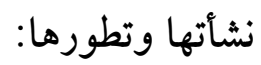

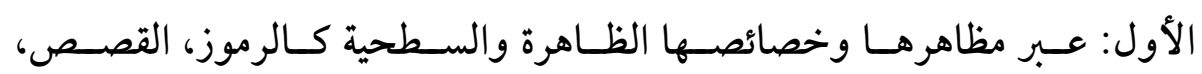

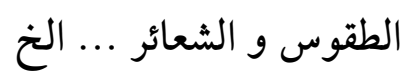

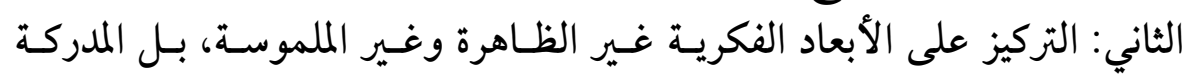

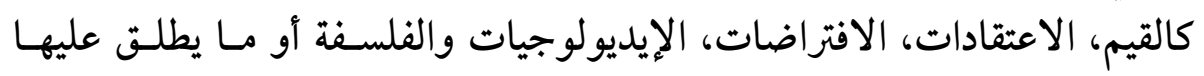
أحيانا جوهر الثقافة. الاعثاد، الاف الثالث: يتمثل في تبني خصائص ثقافية تنظيمية وهو ما يعرف بالنموذج (13) التنظيمي. 
2. تعريف الثقافة التنظيمية:

بجموعة القيم المشتركة التي تحكم تفاعلات أفراد المؤسسة فيما بينهم و مع أمعاد

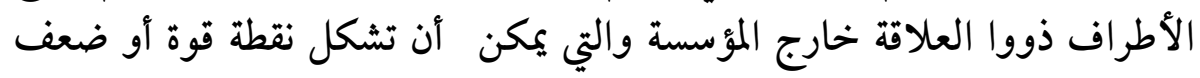

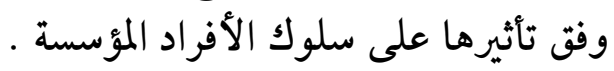

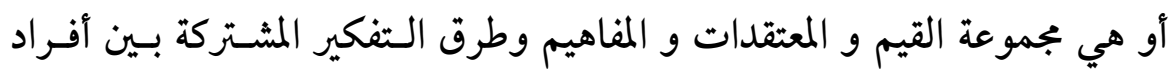
المؤسسة والتي قد تكون غير مكتوبة يتم الشعور بها ويشارك كـل فـرد في تكوينها

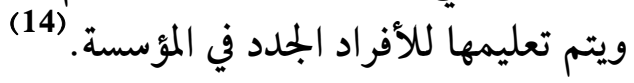

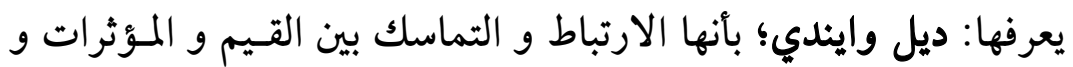

$$
\text { الإشارات التي تحكم تصرفات الأفراد. }
$$

في حين يعرفها كوسن؛ بأنها بجموعة القيم التي يجلبها أعضـاء المؤسسـة (رؤسـاء

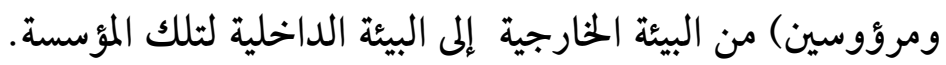

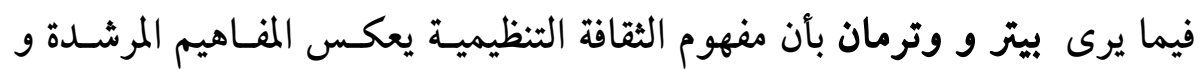

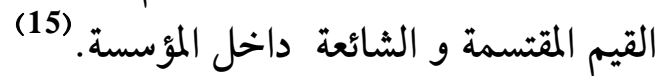

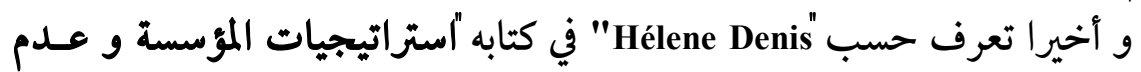

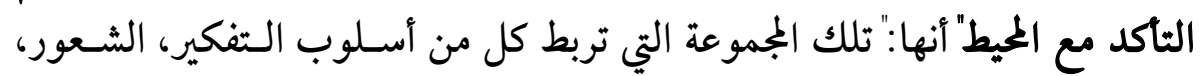

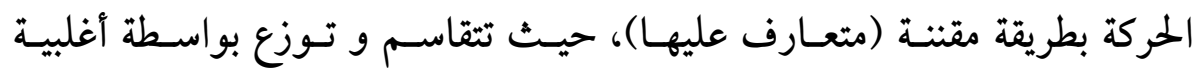

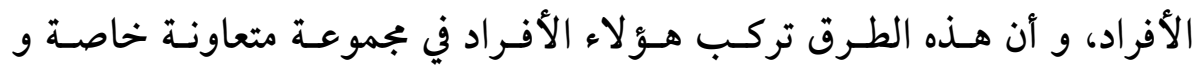
متميزة. هذا تعريف واسع جدا، فالثقافة التنظيمية هي؛ ما يربط بين الأفراد فيما

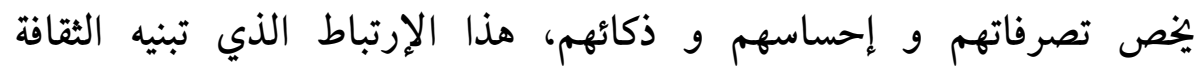

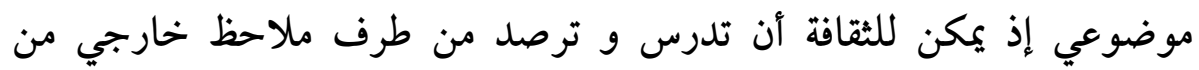

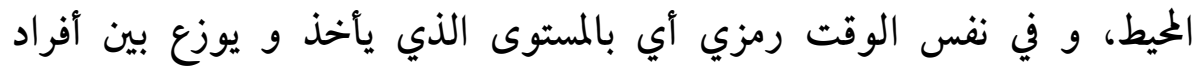

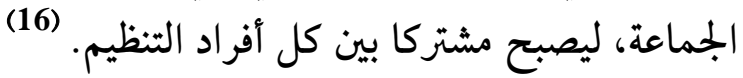

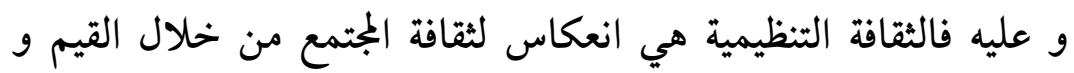

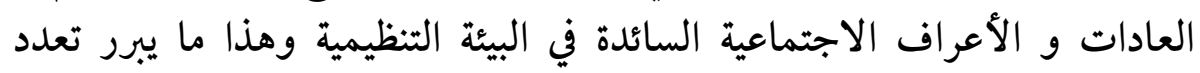


ثقافات المؤسسات كبيرة الحجم، و حتى المتعددة الأجناس نتيجة تعدد ثقافات المجتمع التي تتعامل فيها. كما يمكنا أن نستتجج من التعريفات السابقة أن ثقافة المنظمـة تتكـون مـن ثلاثة عناصر تنظيمية هي: - لمين

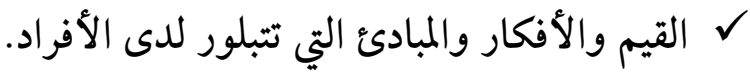

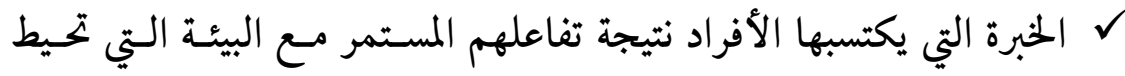

القدرات والمهارات الفنية التي اكتسبها الفرد في حياته.(17) 3. أهمية و أهداف الثقافة التنظيمية:

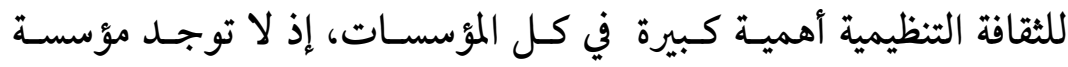

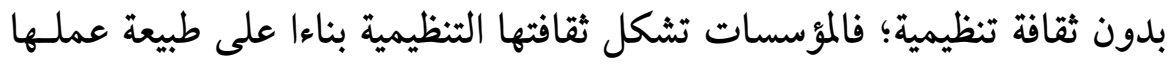

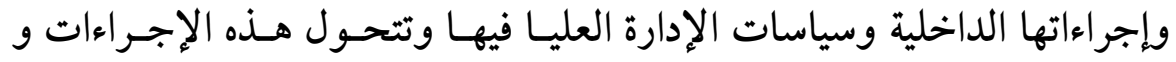

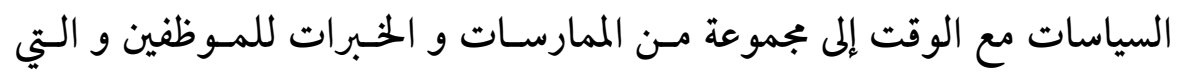
تكون بشكل غير مباشر ثقافة المؤسسة.

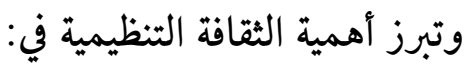
$\checkmark$ لحتق الثقافة التنظيمية النكامل الداخلي في المؤسسة والانسـام الخـارجي بينها وبين بيئتها. تو تعد إطارا فكريا يوجه أعضاء المؤسسة الواحدة و ينظم أعمالهـا علاقـاتهم و انجازاتهم. تعبر الثقافة عن الملامح المميزة للمؤسسة عن غيرها من المؤسسـات وهي كذلك مصدر فخر واعتزاز.

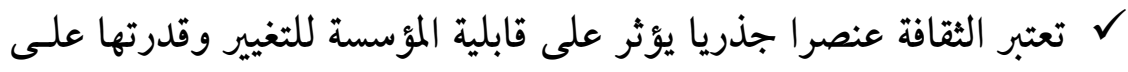

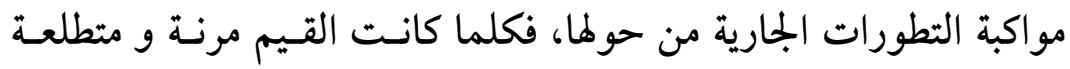
للأفضل كانت المؤسسة أقدر على التغيير و أحرص على التى الإستفادة منهانها،

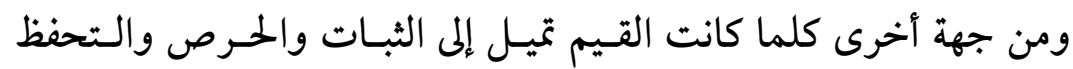
قلت قدرة المؤسسة واستعدادها للتطوير. 


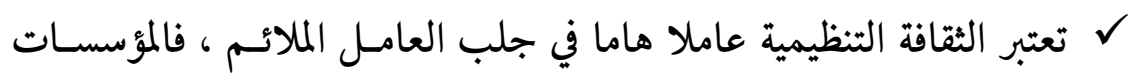

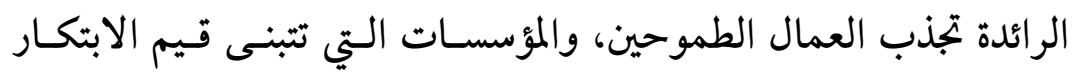

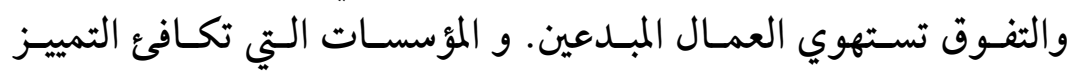

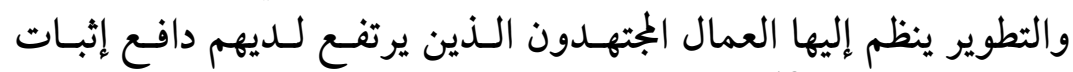
الذات و تحقيقها . (18) هذا و يرجع الاهتمام بالثقافة التنظيمية إلى أنها تؤدي مجموعة من الأهـداف نـذكر

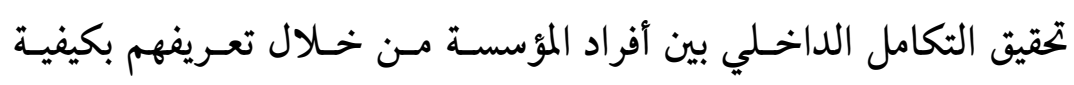

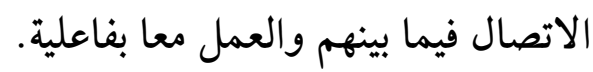

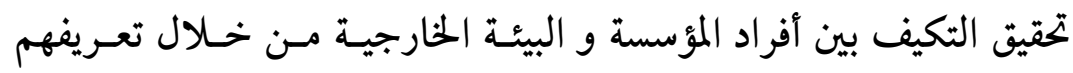

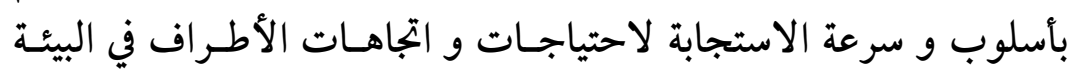
الخارجية ذوي العلاقة بالمؤسسة.

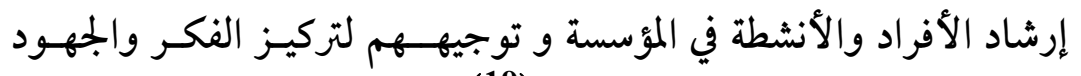
نحو تحقيق أهداف المؤسسة و رسالتها. (19) 4. عناصر و مكونات الثقافة التنظيمية: تتكون الثقافة التنظيمية من عناصر مختلفة أهمها :

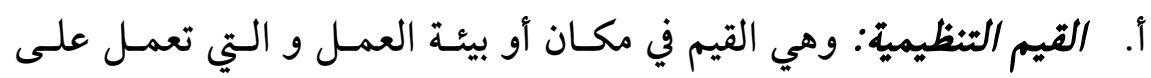

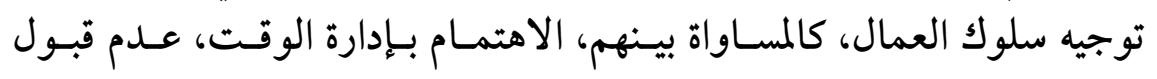

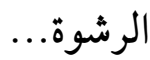
ب. المعتقدات التنظيمية:هي الأفكـار المشتركة حـول طبيعـة العملـ والحيـاة

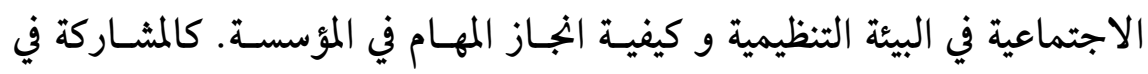

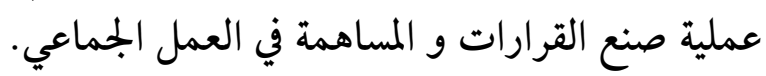

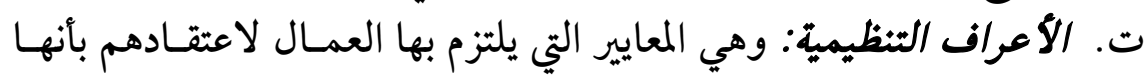

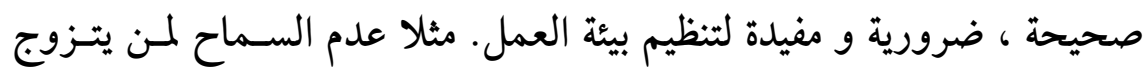

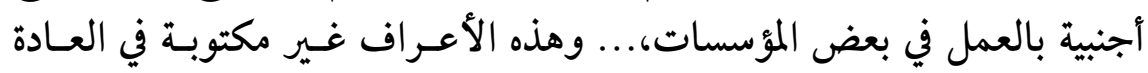
ويجب على أعضاء التنظيم إتباعها . 


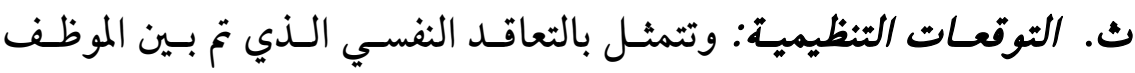

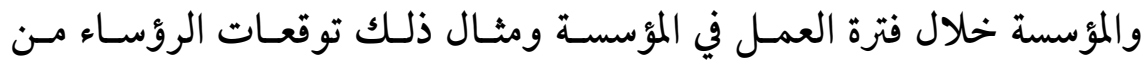

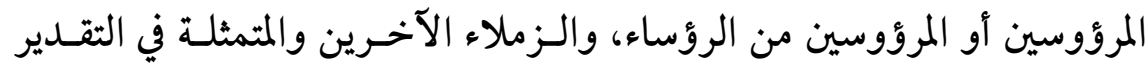

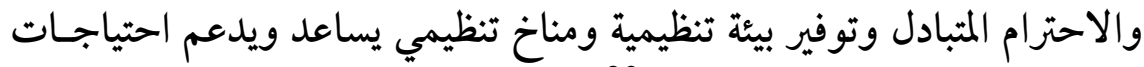
الفرد العامل النفسية والاجتماعية. (20)

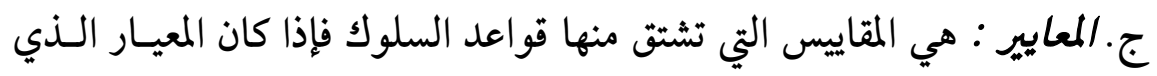

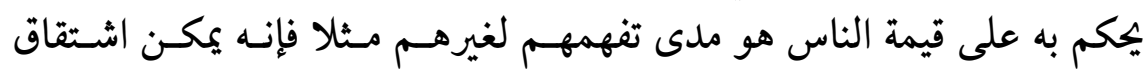

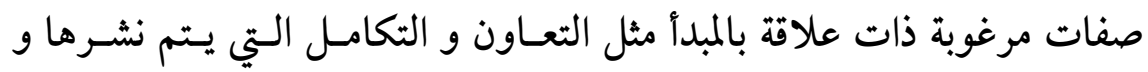
ترسيخها بين العمال.

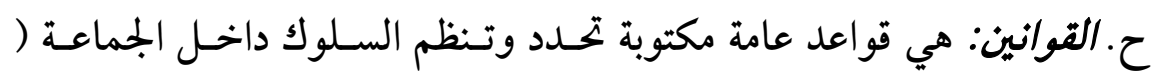

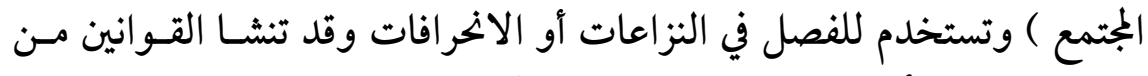

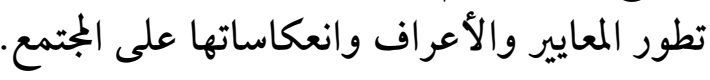

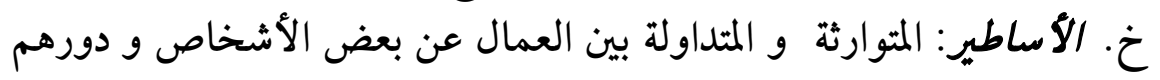

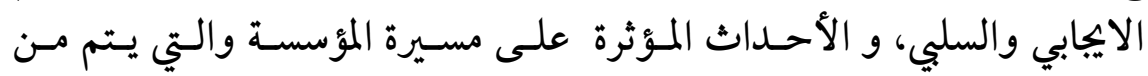

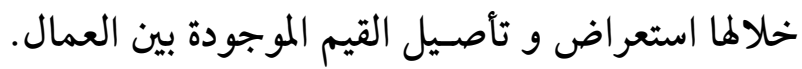

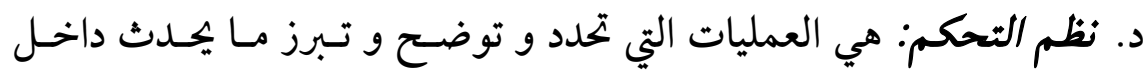

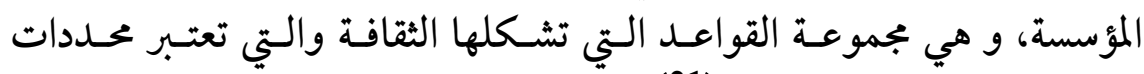
لقو اعد العمل داخل المؤسسة. (21)

ثالثا العلاقة بين الثقافة التنظيمية والتغيير التنظيمي:

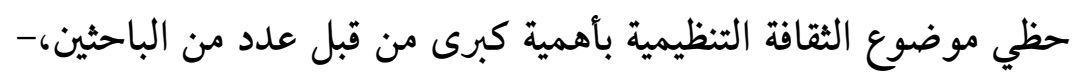

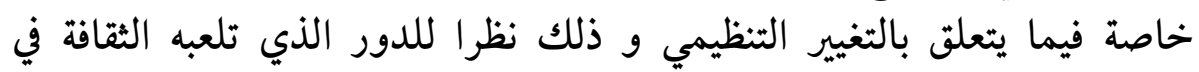

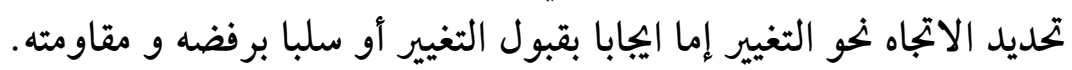

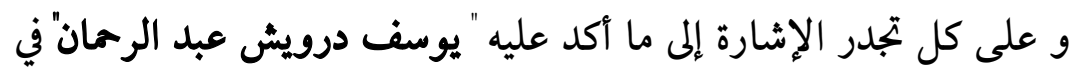

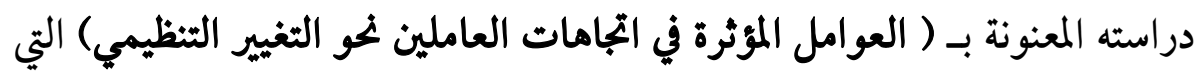

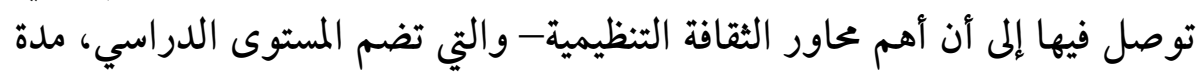


العمل بالمؤسسة، و المسؤولية الشخصية -تؤثر تأثيرا ايجابيا و معنويا في اتجاه

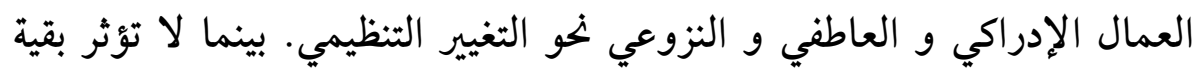

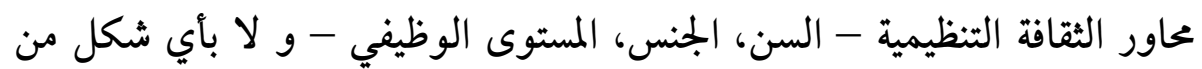
الأشكال في مكونات الاتجاه الثلاثة.

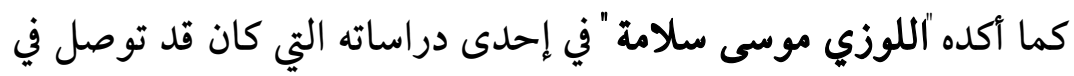

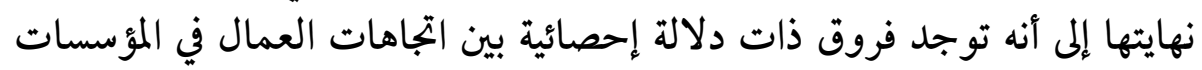

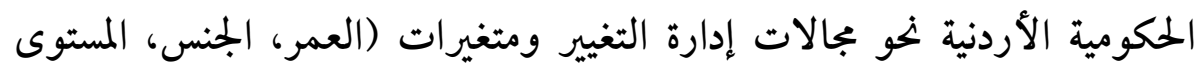

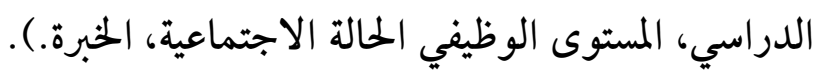

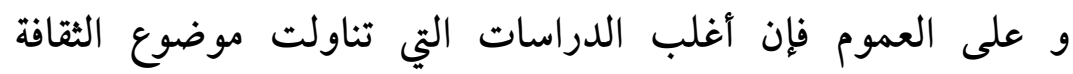

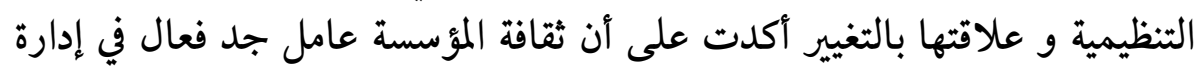

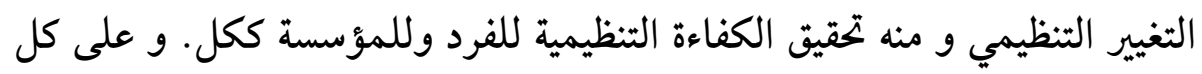

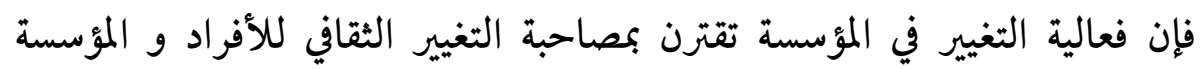

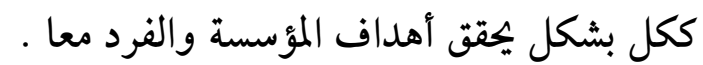
إن القيادة الإدارية تمثل حجر الأساس في نجاح قيادة التغيير.

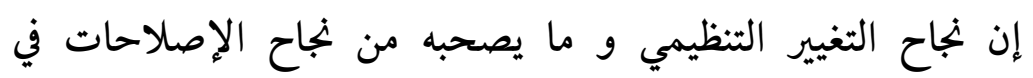

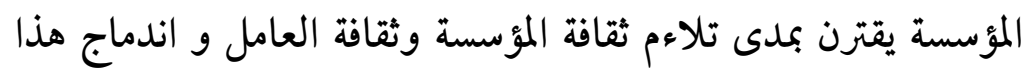

$$
\text { الأخير فيها. }
$$

و بالتالي يمكننا التأكيد على أن كفاءة المؤسسة ترتبط بشكل أساسي

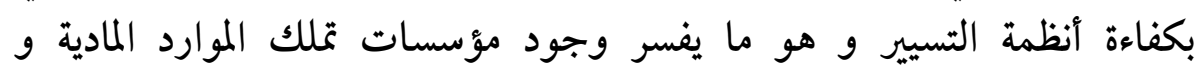

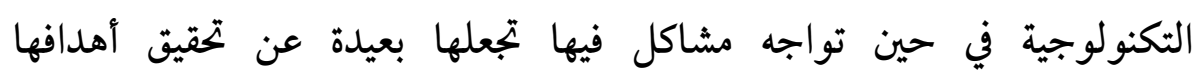

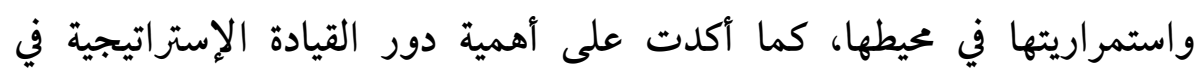

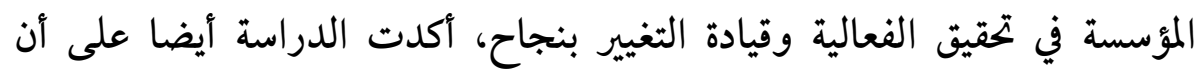

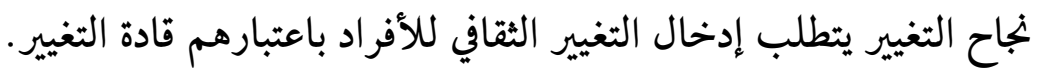

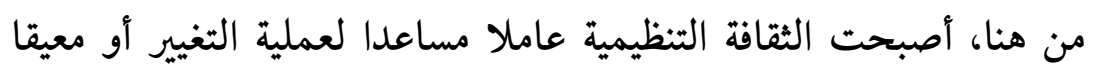

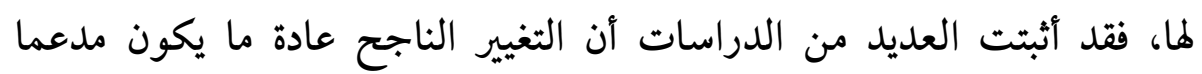


بتغيرات و تطورات ملائمة في كافة النظم الفرعية في المؤسسة بما فيها الثقافة

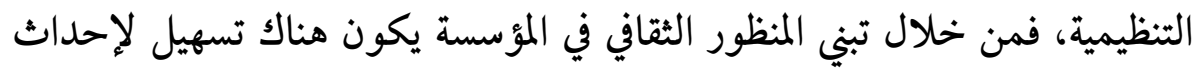

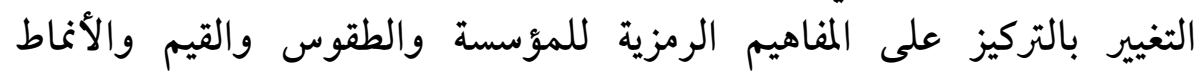

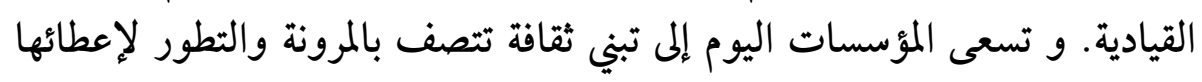

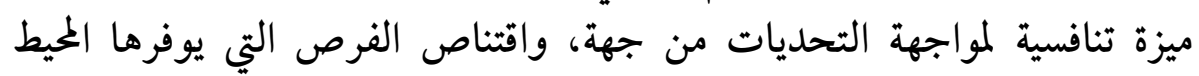

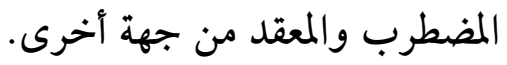


الخاتمة:

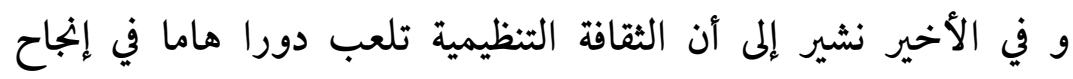

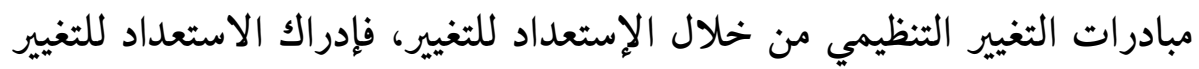

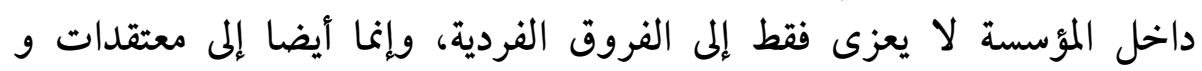

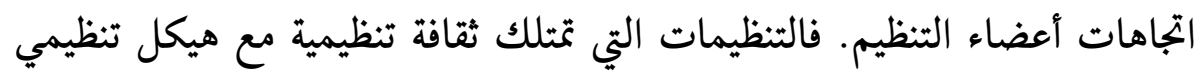

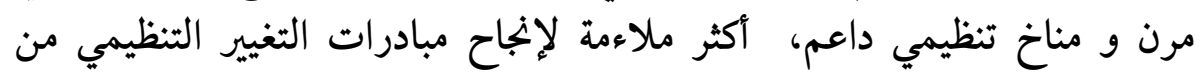

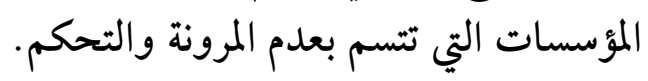

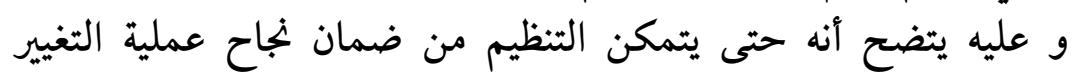

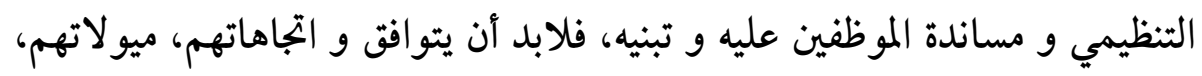

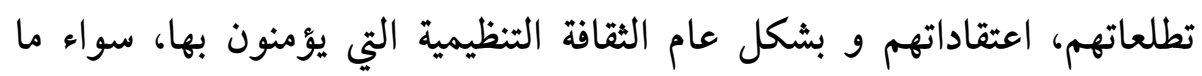

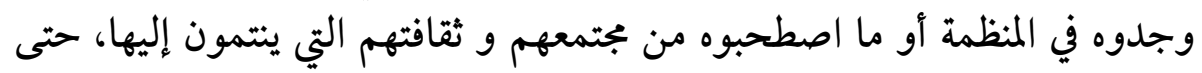

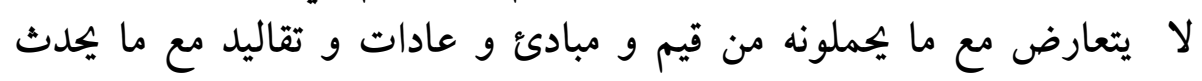

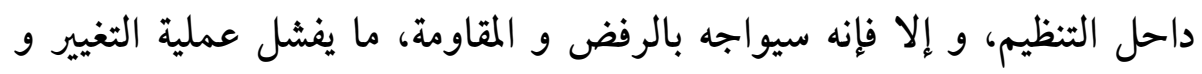

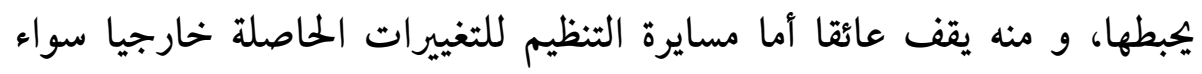
على المستوى المحلي، الاقليمي أو الدولي. 
صلاح الدين محمد عبد الباقي:السلوك الإنساني في المنظمات، الدار الجامعية، مصر،

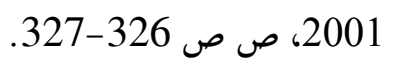

رشيد زرواتي، تدريبات على منهجية البحث العلمي في العلوم الإجتماعية، ط3،ديوان

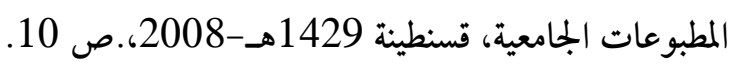

(3) Alain CERCLE, Alain SOMAT,(2005):PSYCHOLOGIE SOCIALE cours et exercices, $2^{\circ}$ éd, édition DUNOD,PARIS.p125.

محمد مسلم: مقدمة في علم النفس الإجتماعي، دار قرطبة، للنشر، الجزائر،2007، ص ص35 -36.

يوسف سعدون: علم الاجتماع و دراسة التغير التنظيمي في المؤسسات الصناعية -دراسة

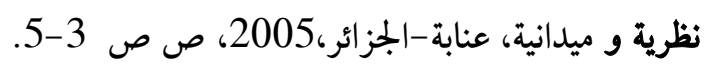

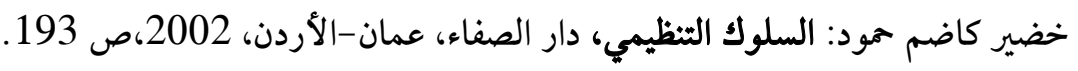

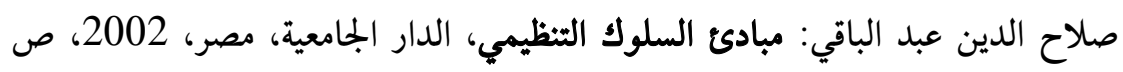

$$
\text { ص }
$$

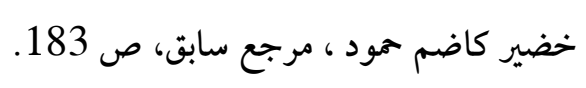

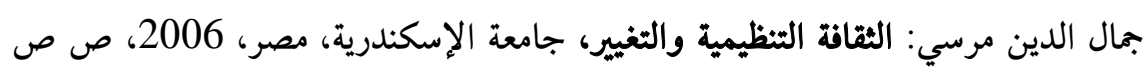

(10) أحمد ماهر:إقتصاديات الإدارة، الدار الجامعية للنشر و التوزيع، الإسكندرية، مصر،

$$
\begin{aligned}
& \text { 2006، ص 435. } \\
& \text { (11) المرجع السابق، ص } 436 .
\end{aligned}
$$

(12)ممد ناصر العديلي: السلوك الانساني في التنظيم ،منظور كلي مقارن، معهد الادارة العامة،

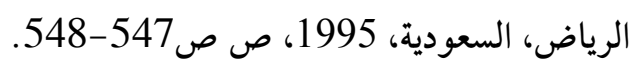

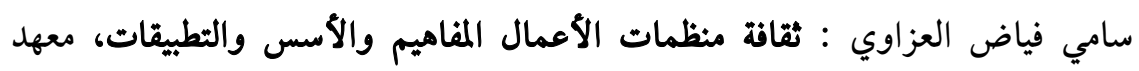

$$
\text { الإدارة العامة، السعودية، ص ص لـ 47-48. }
$$


مصطفى محمود أبو بكر: التنظيم الإداري في المنظمات المعاصرة مدخل تطبيقي، الدار

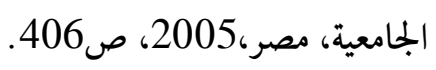

حمود سلمان العميان: الثقافة التنظيمية، دار وائل للنشر و التوزيع، عمان-الأردن، 2002، معند،

$$
\text { ص صود سمان } 309 .
$$

(16) Hélène Dénis, stratégies d'entreprise et incertitudes environnementales, Design organisationnel, culture et technologie, Ed Economica,1990, p 122

موسى سلامة اللوزي وآخرون: السلوك التنظيمي مفاميم معاصرة، إثراء للنشر والتوزيع،

$$
\text { الأردن، } 2009 \text { ص } 265 \text { موسى سلالان }
$$

بلال خلف السكارنة:دراسات إدارية معاصرة، دار المسيرة للنشر والتوزيع، عمان،

$$
\text { 2001، ص بـ (158) } 158
$$

مصطفى محمود أبو بكر:الموارد البشرية مدخل تحقيق الميزة الثنافسية، الدار الجامعية،

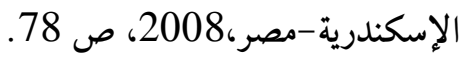

$$
\begin{aligned}
& \text { خضير كاظم حمود، مرجع سابق ، ص ص 266 206 الإسندرية } 267 .
\end{aligned}
$$

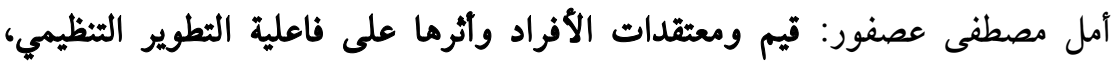

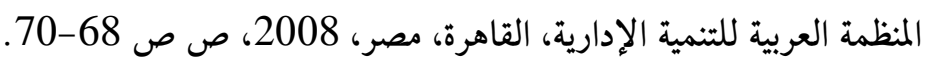


